\title{
A Left Hemithorax Mystery
}

\author{
M. Bernasconi ${ }^{a} \quad$ C.T. Bolliger ${ }^{a} \quad$ E. Irusen ${ }^{a} \quad$ A.H. Diacon ${ }^{a}$ b \\ ${ }^{a}$ Division of Pulmonology, Department of Medicine, and ${ }^{b}$ Division of Medical Physiology, Department of \\ Biomedical Sciences, Tygerberg Academic Hospital, Stellenbosch University, Cape Town, South Africa
}

\section{Case Report}

A 32-year-old mechanic presented with recent onset abdominal pain, nausea and a 1-month history of increasing dyspnoea and productive cough. He was a former smoker (10 pack-years) and reported a single hospital admission 3 years earlier for a stab wound to the left chest. The scars from the stab wound and the intercostal drain inserted for the ensuing pneumothorax were clearly visible on the lateral chest (fig. 1). The patient denied weight loss or other constitutional symptoms.

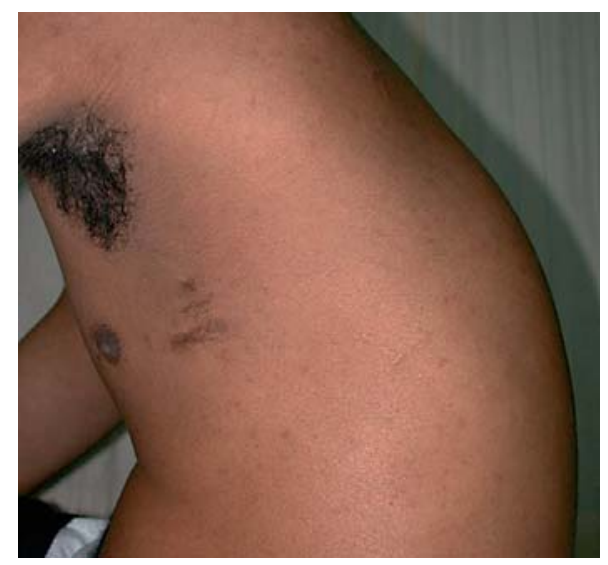

Fig. 1. Lateral chest wall. The scars of the former stab wound and chest drain insertion are visible at the mamillary level.

\section{KARGER}

Fax +4161306 1234

E-Mail karger@karger.ch

www.karger.com
(C) 2011 S. Karger AG, Basel

0025-7931/11/0826-0557\$38.00/0

Accessible online at:

www.karger.com/res
On examination he was sweaty and looked ill. The blood pressure was 140/90 $\mathrm{mm} \mathrm{Hg}$, heart rate 95 beats/ min, axillary temperature $38^{\circ} \mathrm{C}$ and respiratory rate 25/ min. The left hemithorax was dull to percussion and there were decreased breath sounds. The abdomen was found to be soft but tender with normal bowel sounds. Routine full blood counts and serum chemistry were normal, except for a raised white blood cell count of $22 \times$ $10^{9} / 1$ and mildly increased amylase of $351 \mathrm{U} / \mathrm{l}$. The chest radiograph showed an opacified left hemithorax (fig. 2) with a mild mediastinal shift to the right. Diagnostic pleurocentesis was attempted but was dry.

What is your diagnosis?

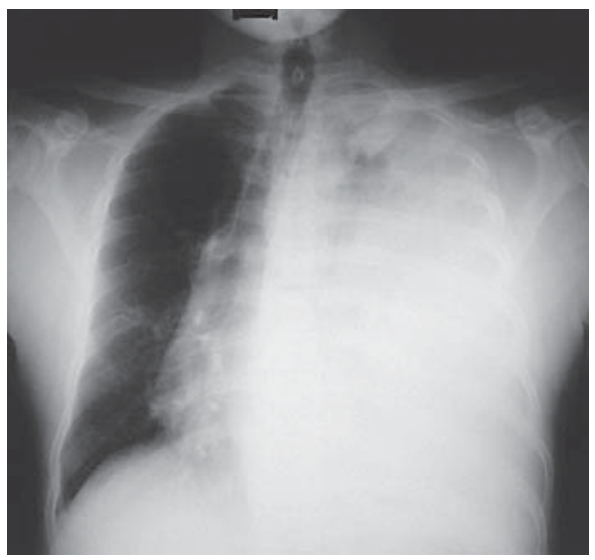

Fig. 2. Posteroanterior chest radiograph at presentation. The left hemithorax is opacified with a mediastinal shift to the right. 


\section{Diagnosis: Diaphragmatic Hernia after Penetrating Left Thoracic Stab Wound}

Computed tomography $(\mathrm{CT})$ of the chest revealed a large defect in the left hemidiaphragm. The colon, omental fat, the small bowel and the tail of the pancreas were visible in the left chest. The left lung was completely compressed (fig. 3). Upon surgical exploration, the bowel was found not to be gangrenous. The hernia was reduced and a diaphragmatic defect was repaired. Complete expansion of the left lung was documented within $24 \mathrm{~h}$ postoperatively (fig. 4). In retrospect, it is likely that the stab injury caused an undiagnosed laceration of the diaphragm, which over the ensuing years allowed progressive herniation of the contents of the abdomen into the left hemithorax. This chronic condition was acutely exacerbated by an episode of sequestration without critical ischemia. The quick recovery of the lung was remarkable.

\section{Discussion}

Stab injuries are a common form of penetrating injury to the chest in our emergency department [1]. Penetrating trauma to the chest can cause injuries to the cardiopulmonary, gastrointestinal, musculoskeletal and lymphatic systems. Due to the large volume and position occupied by the lung in the thoracic cavity, the chest wall, pleura and lung are involved in about $90 \%$ of cases [2]. Because of the large excursion with respiration by the diaphragm, its apex can rise as high as the nipple line (T4 dermatome) upon forced

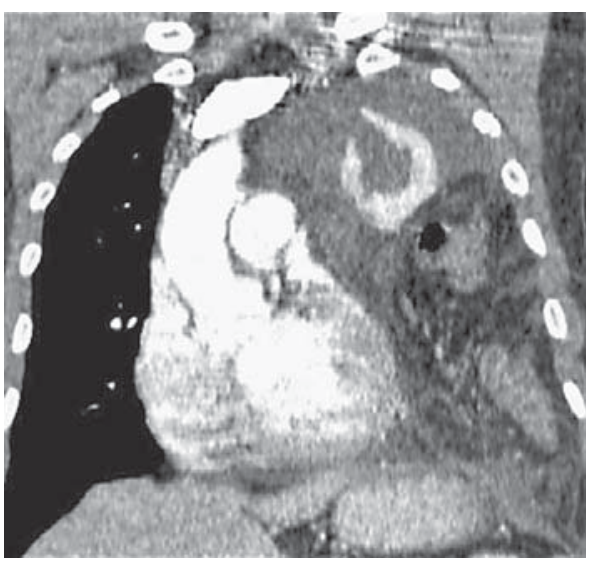

Fig. 3. Contrasted CT of the chest. At the level of the hilum the compressed left lung is seen next to the aorta. The remaining thoracic cavity is filled with herniated omental fat and bowel. expiration. Injuries to the diaphragm can be expected in more than $30 \%$ of patients with penetrating trauma to the thoracoabdominal area [3]. The diagnosis may not be apparent immediately and is missed initially in more than a third of the patients [4]. Typical symptoms such as pleuritic chest pain, dyspnoea, reduced air entry or bowel sounds in the chest are not always present. Only a third of patients exhibit typical signs on chest radiography such intestinal gas collections or a nasogastric tube above the diaphragm. Oral contrast studies, CT, laparoscopy, thoracoscopy and ultrasonography can be of aid in detecting a diaphragmatic injury. The extent of herniation and related complications are best shown by CT. A quick, mobile ultrasound examination at the bedside would probably also have been diagnostic in this particular case $[5,6]$. Ultrasound confirms the indication for pleurocentesis, increases the accuracy of pleural puncture site selection and should be routinely employed before a pleural tap is attempted [7].

In patients with subacute increasing dyspnoea and an opacified hemithorax, the following differential diagnoses should be considered.

Congenital diaphragmatic hernias can develop in the presence of a congenital diaphragmatic defect in a few locations on the diaphragm. The Morgagni hernia is located left paracardial, the Larrey hernia is located right paracardial and the Bochdalek hernia is located posterolateral, more often on the left than the right side. The discovery of such conditions is incidental or prompted by

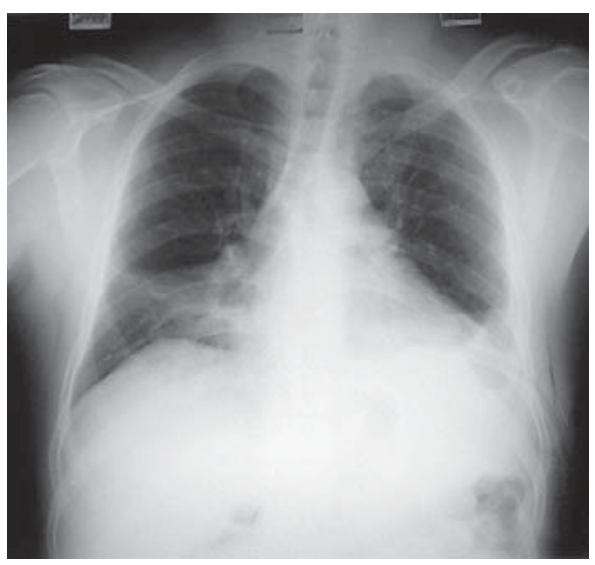

Fig. 4. Posteroanterior chest radiograph $24 \mathrm{~h}$ postoperatively. The left lung is well expanded with the lower lobe still partly atelectatic. 
gastrointestinal or respiratory symptoms [8]. In this particular case these aetiologies were less likely due to the hernia's location and the chronological relationship with the stabbing. Hiatal hernias (sliding and paraoesophageal) are mostly localized in the posterior mediastinum, and are relatively small and asymptomatic.

Tuberculous pleurisy is a relatively acute febrile illness causing a non-productive cough, weight loss, pleuritic chest pain, night sweats and dyspnoea. Tuberculous pleural effusions are mostly unilateral and small to moderate in size. Effusions occupying the whole hemithorax can occur, but these are associated with considerable mediastinal shift to the contralateral side [9]. Elevation of the peripheral white blood cell count is, moreover, not typical. A pleural tap would have yielded straw-coloured fluid.

Chronic, loculated empyema as a late complication after a penetrating chest injury could explain the dry tap, raised temperature and elevated white cell count. However, one would expect a mainly pleural-based opacification on the chest X-ray, combined with signs of volume loss such as rib crowding, an elevated hemidiaphragm and a mediastinal shift to the side of the empyema [10].

A ruptured posttraumatic arteriovenous aneurysm with haemothorax is a rare complication after a chest stab wound. In this case, the lack of anaemia and symptoms of haemodynamic shock ruled this out.

Amoebiasis is endemic in South Africa and causes fever as well as non-specific abdominal symptoms. Thoracic involvement is not uncommon and is usually due to the rupture of an amoebic liver abscess through the diaphragm into the chest cavity. However, such effusions are usually small and situated on the right side [11].

Left main bronchus obstruction would be expected to result in a pronounced volume loss on the left side with an associated ipsilateral mediastinal shift.

\section{Management of Left Thoracoabdominal Stab Wounds}

Most patients with stab injuries to the chest without signs of cardiac or major vascular injury require only chest tube drainage as definitive management [12]. Patients with penetrating stab wounds to the lower chest, however, are at risk of a diaphragmatic injury with high morbidity and mortality if not recognized and treated promptly. The most feared complications are bowel gangrene and perforation [4].

In the authors' institution, haemodynamically stable patients with left-sided stab wounds below the nipple line are routinely evaluated by elective laparoscopy in order to rule out diaphragmatic lesions or to perform the immediate repair thereof. This approach is supported by a recent study that reported a high prevalence of diaphragmatic or intra-abdominal injuries in such patients, and demonstrated the possibility of laparoscopic repair during the same session [3].

\section{Key Words}

Thoracic injury • Diaphragmatic hernia • Pleural effusion • Ultrasound

\section{Financial Disclosure and Conflicts of Interest}

No authors have any actual or potential conflicts of interest, including financial, personal or other relationships that could influence or bias this work.

\section{References}

-1 Schuurmans MM, Davel S, Diacon AH: Nonresponding 'tension pneumothorax' following stab wounds. Respiration 2003;70:100.

2 Oparah SS, Mandal AK: Penetrating stab wounds of the chest: experience with 200 consecutive cases. J Trauma 1976;16:868-872.

-3 Yucel T, Gonullu D, Matur R, Akinci H, Ozkan SG, Kuroglu E, et al: Laparoscopic management of left thoracoabdominal stab wounds: a prospective study. Surg Laparosc Endosc Percutan Tech 2010;20:42-45.

-4 Degiannis E, Levy RD, Sofianos C, Potokar T, Florizoone MG, Saadia R: Diaphragmatic herniation after penetrating trauma. $\mathrm{Br} \mathrm{J}$ Surg 1996;83:88-91.

\footnotetext{
Froudarakis ME: Diagnostic work-up of pleural effusions. Respiration 2008;75:4-13. 6 Anantham D, Herth FJ, Majid A, Michaud G, Ernst A: Vibration response imaging in the detection of pleural effusions: a feasibility study. Respiration 2009;77:166-172.

$\checkmark 7$ Diacon AH, Brutsche MH, Soler M: Accuracy of pleural puncture sites: a prospective comparison of clinical examination with ultrasound. Chest 2003;123:436-441.

-8 Horton JD, Hofmann LJ, Hetz SP: Presentation and management of Morgagni hernias in adults: a review of 298 cases. Surg Endosc

Sibley JC: A study of 200 cases of tuberculous pleurisy with effusion. Am Rev Tuberc 1950; 62:314-323.

10 Koegelenberg CF, Diacon AH, Bolliger CT: Parapneumonic pleural effusion and empyema. Respiration 2008;75:241-250.

11 Shamsuzzaman SM, Hashiguchi Y: Thoracic amebiasis. Clin Chest Med 2002;23:479492.

12 Demetriades D, Rabinowitz B, Markides N Indications for thoracotomy in stab injuries of the chest: a prospective study of 543 patients. Br J Surg 1986;73:888-890.
} 2008;22:1413-1420. 